\title{
The intermittent punishment effect in humans: Conditioning or adaptation? ${ }^{1}$
}

ROSS D. PARKE, JAN L. DEUR, and DOUGLAS B. SAWIN, ${ }^{2}$ University of Wisconsin, Madison, Wis. 53706

Human Ss were trained under $100 \%$ reward, 50\% punishment-50\% reward, or $100 \%$ reward, with exposure to the punishing stimulus on a noncontingent basis. Following acquisition, $S s^{\prime}$ resistance to continuous punishment was assessed. The $50 \% P-50 \% R$ group persisted longer under continuous punishment than either of the 100\% reward groups. Since exposure to noncontingent punishment did not increase resistance to continuous punishment, an adaptation-to-punishment explanation of the persistence of $50 \% P-50 \% R$ Ss was eliminated in favor of a conditioning interpretation.

In a recent experiment, Deur \& Parke (1968) found that resistance to a continuous punishment could be increased by exposing adult human Ss to punishment on an intermittent basis during acquisition. This phenomenon has been labeled the intermittent punishment effect (IPE). Using a button-pressing task, it was found that Ss trained under $50 \%$ reward-50\% punishment persisted longer during subsequent continuous punishment than did Ss trained on $100 \%$ reward. These data were interpreted as supporting extensions of Amsel's theory of frustrative nonreward (Banks, 1966; Martin, 1963) to punishment situations. Briefly, it is argued that intermittently rewarding and punishing a response will result in the classical conditioning of anticipatory punishment responses to the approach response, thus resulting in greater persistence during continuous punishment. This interpretation assumes that the critical aspect of the intermittent punishment treatment employed by Deur \& Parke (1968) was the pairing of the punisher with the same response that was occasionally rewarded. However, a more parsimonious interpretation of this partial-punishment effect is possible.

In addition to providing the 50\% reward-50\% punishment group the opportunity for the classical conditioning of anticipatory punishment responses to the correct response, these Ss were also provided with the opportunity to adapt to the punishing stimulus. There is evidence that an organism will adapt to a noxious stimulus, thus rendering this stimulus less effective for producing response suppression (Azrin, 1960). It is possible that adaptation to the buzzer employed as the punisher was the critical factor in the intermittent-punishment effect.

The aim of this study was to determine whether or not this alternative explanation was correct. An adequate test of these competing positions requires that, in addition to a group of Ss that is exposed to the critical pairing of the punishment with the rewarded response, a second group be exposed to an equal number of punishment presentations to equate the groups for adaptation. For the latter group, the Ss must be exposed to the punisher on a noncontingent basis so that no opportunity for the conditioning of anticipatory punishment responses to approach responses is allowed. If the adaptation interpretation is correct, all groups exposed to the punisher, regardless of whether or not punishment was contingent on the button-pressing response, will show greater resistance to continuous punishment of button pressing than will groups having no prior exposure to the punishment. On the other hand, the conditioning interpretation predicts that only the groups receiving contingent punishment training will show the intermittent punishment effect. METHOD

The Ss were 45 male introductory psychology students at the University of Wisconsin who received points toward their final grade for participating in the experiment. Fifteen Ss were assigned randomly to each of the three experimental conditions.

\section{APPARATUS}

The button-pressing apparatus consisted of the three-button response panel previously described by Deur \& Parke (1968). On one corner of the panel was a small white light that $E$ used to signal the onset of a trial. On the same circuit was a three-light panel, visible only to $E$, that indicated the $S$ 's response sequence for each trial. $S$ and $E$ sat on opposite sides of a table divided by a Masonite screen to eliminate visual contact. An aluminum tube passed through the screen, allowing $\mathrm{E}$ to deliver penny rewards into a box on the S's side of the table.

The second apparatus employed in this study consisted of an amber light that signaled $S$ to push a foot pedal on the floor by his right foot.

The buzzer used for both tasks was an Edwards No. 115 model, operated at $18 \mathrm{~V}$. A General Radio Co. sound-level meter,
Type 155I-C, indicated that the loudness of the buzzer was $85 \mathrm{~dB}$. The duration of the buzzer was automatically timed at $3 \mathrm{sec}$.

\section{PROCEDURE}

Each $S$ was brought from a waiting room in to the experimental room by $\mathbf{E}$, a student in his late twenties, who played recorded instructions for $S$. S was informed that the experiment consisted of two independent and unrelated tasks: a button-pressing task that determined how well $S$ could learn a correct response sequence (e.g., 3-1-2, 1-3-2) and a second task that involved depressing a food pedal. With regard to the first task, $S$ was told to accumulate as many pennies as possible by pressing a three-button sequence on the response panel each time the white signal light flashed. $S$ was also told that a response sequence might be followed by a punishment that consisted of a loud buzzer.

With regard to the second task, $\mathbf{S}$ was told to depress the foot pedal whenever the amber light flashed. This occurred after each trial on the button-pressing task. On some occasions a buzzer followed the foot-pedal response. The instructions stressed that this buzzer had no relation to, or effect on, their performance on the first task. Finally, each $S$ was told that he could end the experiment any time simply by asking $\mathrm{E}$ to stop.

Following the instructions, E sat behind the screen where he signaled the beginning of each trial by a signal light, recorded the $S$ 's response sequence, and delivered the appropriate rewards and punishments. As in the previous study (Deur \& Parke, 1968), the first two trials on the button-pressing task were not reinforced, and the response sequence on the third trial was arbitrarily chosen as the goal response. The first goal response was reinforced with a penny for all Ss. Acquisition continued until a criterion of 20 goal responses was met. No rewards were dispensed for any sequence other than the goal-response sequence, and reinforcers immediately followed the completion of each goal-response sequence.

There were three acquisition conditions: continuous reward $(100 \% \mathrm{R})$, continuous reward, with 10 noncontingent presentations of the buzzer (100\%R-10NCB), and 50\% reward-50\% punishment (50\%R-50\%P). In the $50 \% \mathrm{R}-50 \% \mathrm{P}$ group, 10 of the goal responses on the button-pressing task were rewarded and 10 were punished. The partial reinforcement schedule for the button-pressing task was generated randomly, with the restrictions that the first two and the last goal responses were rewarded and that no more than two 
rewards or two punishments were consecutive. The buzzer for the $100 \%$ R-10NCB group was sounded immediately following the foot-pedal press on 10 of the goal-response trials. The schedule for the 10 noncontingent buzzers was generated randomly, with the restriction that an equal number occurred following positively and negatively reinforced goal-response trials.

After 20 goal responses were reinforced, Ss in all three groups entered a continuous punishment (CP) period in which all goal responses on the button-pressing task were continuously punished. All rewards were discontinued and no buzzer followed the foot-pedal response.

The dependent measure was the number of goal responses made by $S$ during the $C P$ phase before the $S$ terminated the experiment. For the five Ss who did not voluntarily end the experiment, E terminated the experiment after $60 \mathrm{~min}$ and credited $S$ with the number of goal responses emitted up to that point.

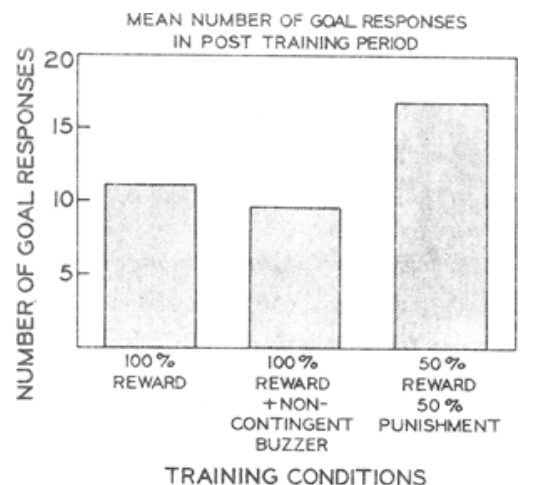

Figure 1
Additional Ss were run but dropped before the analysis of the data because six of them voluntarily ended the experiment before acquisition was completed and nine failed to follow the instructions. The $S$ loss was distributed fairly evenly across experimental groups.

\section{RESULTS AND DISCUSSION}

The mean number of goal responses for each of the three groups following acquisition is presented in Fig. 1. A square-root transformation was applied to the data to permit parametric analysis to be carried out. As predicted, Ss trained on $50 \%$ reward-50\% punishment emitted more goal responses than did Ss trained on $100 \%$ reward with no noncontingent buzzer presentations $(t=1.75$, df $=28, p<.05$, one-tailed test). This finding confirms results from previous investigations (Banks, 1966; Deur \& Parke, 1968, 1970). In addition, Ss trained on $50 \%$ reward $-50 \%$ punishment persisted longer than $\mathrm{Ss}$ trained on $100 \%$ reward with 10 presentations of the noncontingent buzzer $(\mathrm{t}=2.18, \mathrm{df}=28, \mathrm{p}<.05$, two-tailed test $)$. This finding fails to support an adaptation-to-punishment explanation of the intermittent punishment effect for human Ss. The pattern of results is consistent with a frustration-theory interpretation that asserts that the mechanism underlying the IPE is the classical conditioning of anticipatory punishment responses resulting from the administration of contingent reward and punishment to the goal response (Banks, 1966).

Although no support for an adaptation-to-punishment interpretation was found, further research is required in which a wider range of intensities of the noxious stimulus is employed, since the opportunity for adaptation may be more important at higher intensity levels.

Alternative procedures for the adaptation control condition were considered but eliminated. One procedure involved the presentation of the punisher on a randomly delayed basis following a button-pressing trial. However, pilot work for the present study indicated that Ss would generate hypotheses linking the noncontingent aversive event and their performance on the button-pressing task. Even when the present procedure was adopted, in which the punishment was associated with a different ask, instructions stressing the fact that the tasks were unrelated were necessary to control S-generated associations and thereby permit an unequivocal test of the conditioning vs adaptation positions.

\section{REFERENCES}

AZRIN, N. H. Sequential effects of punishment. Science, 1960, 131, 605-606.

BANKS, R. K. Persistence to continuous gunishment following intermittent punishment training. Journal of Experimental Psychology, 1966, 71, 373-377.

DEUR, J. L., \& PARKE, R. D. Resistance to extinction and continuous punishment in humans as a function of partial reward and partial punishment training. Psychonomic Science, 1968, 13, 91-92.

DEUR, J. L., \& PARKE, R. D. The effects of inconsistent punishment on aggression in children. Developmental Psychology, in press.

MARTIN, B. Reward and punishment associated with the same goal response: $A$ factor in the learning of motives. Psychological Bulletin, $1963,60,441-451$.

\section{NOTES}

1. The research reported in this paper was supported in part by National Science Foundation Grant GS-1847 to the senior author and by United States Public Health Service Training Grant $144-8920$ from the National Institute of Mental Health.

2. Now at the Institute of Child Development, University of Minnesota. 